\title{
Exploring the genetic diversity of shallow-water Agariciidae (Cnidaria: Anthozoa) from the Saudi Arabian Red Sea
}

\author{
Tullia I. Terraneo $^{1}$ - Roberto Arrigoni ${ }^{1} \cdot$ Francesca Benzoni $^{2,3} \cdot$ Matthew D. Tietbohl $^{1}$. \\ Michael L. Berumen ${ }^{1}$
}

Received: 1 October 2016 / Revised: 26 April 2017 / Accepted: 26 April 2017

(C) Senckenberg Gesellschaft für Naturforschung and Springer-Verlag Berlin Heidelberg 2017

\begin{abstract}
Scleractinian corals ascribed to the family Agariciidae represent an important component of Red Sea coral reef fauna, though little genetic data are currently available for this group, and existing information shows polyphyly in the examined mesophotic taxa from the Pacific Ocean. In this work, we provide a first genetic survey of Agariciidae from the Saudi Arabian Red Sea, based on a collection of shallow-water material $(<30 \mathrm{~m})$ from the Gulf of Aqaba to the Farasan Islands. Two molecular markers were sequenced to infer morphospecies monophyly and relationships, the intergenic region between COI and 16S rRNA from mitochondrial DNA and the ribosomal ITS1 region from nuclear DNA. A total of 20 morphospecies were identified based on classical macromorphological characters. Six, namely Gardineroseris planulata, Pavona maldivensis, Pavona clavus, Pavona decussata, Leptoseris fragilis, and Leptoseris yabei, were resolved with both DNA loci. The molecular boundaries among the remaining 14 species remain unclear. Our results further confirm that the morphology-based taxonomy of most agariciid species is in disagreement with
\end{abstract}

Tullia I. Terraneo and Roberto Arrigoni contributed equally to this work.

Communicated by M. Sonnewald

Tullia I. Terraneo

tulliaisotta.terraneo@kaust.edu.sa

1 Red Sea Research Center, Division of Biological and Environmental Science and Engineering, King Abdullah University of Science and Technology, Thuwal 23955-6900, Saudi Arabia

2 UMR ENTROPIE (IRD, Université de La Réunion, CNRS), Laboratoire d'Excellence-CORAIL, Centre IRD de Nouméa, New Caledonia, 101 Promenade Roger Laroque, BP A5, 98848 Noumea Cedex, New Caledonia

3 Department of Biotechnologies and Biosciences, University of Milano-Bicocca, Piazza della Scienza 2, 20126 Milan, Italy genetics. In order to disentangle the systematics of these taxa, the inclusion of more sampling locations, additional variable loci, and a micromophological approach are likely needed. Our genetic data represent a first step towards the comparison of biodiversity and connectivity between the Red Sea and the rest of the Indo-Pacific.

Keywords Coral $\cdot$ Systematics $\cdot$ Biodiversity $\cdot$ IGR $\cdot$ ITS $~$. Phylogenetics · DNA taxonomy

\section{Introduction}

The Red Sea (RS) is a north-south orientated and semienclosed basin at the northwestern corner of the Indian Ocean (IO). It is connected to the IO only at the narrow $(18 \mathrm{~km})$ and shallow $(137 \mathrm{~m})$ Strait of Bab al Mandab (Sheppard et al. 1992). Despite its modest surface area $\left(438,000 \mathrm{~km}^{2}\right)$, the total coral reef area of the RS (c. 8890 $\left.\mathrm{km}^{2}\right)$ is similar to that of the Caribbean (c. $\left.10,530 \mathrm{~km}^{2}\right)$ and its reef system length $(\mathrm{c} .2000 \mathrm{~km})$ is comparable to that of the Great Barrier Reef(GBR) (c. 2300 km) (Berumen et al. 2013). The RS has long been recognized as a region of high marine biodiversity and endemism (Klunzinger 1870, 1877; Ekman 1953). The unique reef fauna of the RS has multiple evolutionary origins (DiBattista et al. 2016a), with some taxa originating within the RS during the Pleistocene glaciations (DiBattista et al. 2015; Coleman et al. 2016) and others diverging from their IO sister groups long before the last glacial cycles (DiBattista et al. 2013; Hodge et al. 2014).

In the RS, $5.5 \%$ of the 364 scleractinian coral species are endemic (DiBattista et al. 2016b). whereas levels of endemism for scleractinians is typically less than $2 \%$ in the IO (Obura 2012; Veron et al. 2015). However, our knowledge of the coral ecology and biodiversity of the RS is limited compared to 
other major reef systems, e.g., the GBR and the Caribbean (Berumen et al. 2013). While the Gulf of Aqaba (GofA) has been the source of notable and seminal works in the field of coral reef ecology and taxonomy (Loya et al. 2014), the restricted area of the GofA ( $<2 \%$ of the RS) may preclude extrapolation to the broader RS. RS corals attracted the attention of early taxonomists (e.g., Forskål 1775; Lamarck 1816; Ehrenberg 1834; Klunzinger 1877) and were later the subject of more detailed surveys and larger reference collections (e.g., Scheer and Pillai 1983; Sheppard and Sheppard 1991). These publications, representing milestones for coral taxonomy in the RS, are based on classical morphology-based taxonomy, providing detailed descriptions of coralla and corallite features at the macroscopic scale. Recently, molecular works coupled with analyses of the macro- and micromorphology of the skeletons have allowed the description of new reef corals in the RS (Terraneo et al. 2014; Arrigoni et al. 2015, 2016a, b, 2017) and have showed unexpectedly low genetic diversity for some genera previously thought to have high species richness in this region (Terraneo et al. 2016; Arrigoni et al. 2016c). Moreover, other genetic surveys have revealed several cases of genetic differentiation between Indian and Pacific coral populations previously obscured by traditional taxonomy (Stefani et al. 2011; Ladner and Palumbi 2012; Arrigoni et al. 2012; Kitano et al. 2014; Richards et al. 2016).

To date, the scleractinian coral family Agariciidae Gray, 1847 comprises seven genera (Kitahara et al. 2012) and 49 extant species (WoRMS 2016). The genus Pachyseris Milne Edwards \& Haime, 1849 was also ascribed to the family (Vaughan and Wells 1943; Wells 1956; Veron and Pichon 1980). Nevertheless, recent molecular works provide evidence that Pachyseris is not closely related to the Agariciidae and, instead, is basal to the family Euphylliidae Alloiteau, 1952 (Fukami et al. 2008; Kitahara et al. 2010); the position of the genus remains uncertain. Within the family, the genera Coeloseris Vaughan, 1918, Dactylotrochus Wells, 1954, Gardineroseris Scheer \& Pillai, 1974, and Pavona Lamarck, 1801 occur in the Indo-Pacific; Agaricia Lamarck, 1801 and Helioseris Milne Edwards \& Haime, 1849 occur in the Western Atlantic; and Leptoseris Milne Edwards \& Haime, 1849 occurs in both the Indo-Pacific and the Atlantic Ocean. Agariciids are common in tropical shallow-water coral reefs $(<30 \mathrm{~m}$ ) throughout their distribution range (Veron 2000; Waheed and Hoeksema 2014; Waheed et al. 2015). Moreover, representatives of Leptoseris and Agaricia may be a dominant component of mesophotic coral ecosystems (Fricke et al. 1987; Hinderstein et al. 2010; Rooney et al. 2010; Kahng et al. 2014) occurring in the tropics and subtropics between depths of $30 \mathrm{~m}$ to over $150 \mathrm{~m}$ (Kahng et al. 2010). For example, Leptoseris fragilis Milne Edwards \& Haime, 1849 has been found at $145 \mathrm{~m}$ in the GofA (Fricke and Knauer 1986) and Leptoseris hawaiiensis Vaughan, 1907 at $165 \mathrm{~m}$ from Johnston Atoll (Maragos and Jokiel 1986). In the RS, species of Gardineroseris and Pavona are commonly found between 1 and $20 \mathrm{~m}$ depth, while most species of Leptoseris are more abundant in low-light conditions under reef overhangs or below $30 \mathrm{~m}$, where they can be a major component of coral coverage (Scheer and Pillai 1983; Sheppard and Sheppard 1991). Notably, Leptoseris has been recorded from over $100 \mathrm{~m}$ depth (Fricke et al. 1987). Scheer and Pillai (1983) listed 15 species of Agariciidae from the Saudi Arabian RS, Sheppard and Sheppard (1991) listed 16 species from the Saudi Arabian RS, and Veron (2000) listed 19 species from the entire RS (see Table 1 for the complete list of species reported by these three publications). Subsequently, Leptoseris amitoriensis Veron, 1990 was reported for the first time in the RS by Ziegler et al. (2015).

Despite the ecological importance of this family, its taxonomy and systematics are still almost entirely based on traditional studies of skeletal morphology (Dinesen 1980; Veron and Pichon 1980; Veron 2000). The definition of agariciid genera and species boundaries occurred prior to the introduction of molecular techniques that have revolutionized coral systematics at all taxonomic ranks (Kitahara et al. 2016). A detailed morpho-molecular approach by Kitahara et al. (2012) demonstrated that the solitary and deep-water species Dactylotrochus cervicornis (Moseley, 1881), previously ascribed to the Caryophylliidae Dana, 1846, is the oldest extant representative of Agariciidae. Phylogenetic investigations of the Hawaiian mesophotic Leptoseris and Pavona species based on the mitochondrial intergenic region between COI and 16S rRNA (IGR hereafter) showed that the two genera are not monophyletic and revealed several hidden species (Luck et al. 2013; Pochon et al. 2015). Other integrative works focusing on species delimitation among shallow-water species of Pavona found genetic distinction between Pavona chiriquiensis Glynn, Mate \& Stemann, 2001 and Pavona varians Verrill, 1864 from Panama (Maté 2003), between Pavona cactus Forskål, 1775 and Pavona decussata Dana, 1846 from Mauritius (Moothien Pillay et al. 2006), and between Pavona maldivensis (Gardiner, 1905) and Pavona explanulata (Lamarck, 1816) from Malaysia (Waheed et al. 2015). However, the data produced in the above studies are only partially comparable because they are based on different molecular techniques or distinct loci with variable resolutions; they also typically represent single cases and do not address the whole spectrum of diversity within the family.

In this work, we present the first survey of the genetic diversity of shallow-water $(<30 \mathrm{~m})$ Agariciidae from the Saudi Arabian RS for the morphospecies encountered during different biodiversity surveys organized by the King Abdullah University of Science and Technology (KAUST). The skeletal macromorphology of the collected material was used to identify the specimens based on existing taxonomic references and, when possible, through comparison with type material. Two molecular markers, i.e., mitochondrial IGR and internal 
Table 1 List of Agariciidae species recorded from the Red Sea (RS) by Scheer and Pillai (1983), Sheppard and Sheppard (1991), Veron (2000), and this study

\begin{tabular}{|c|c|c|c|c|}
\hline & $\begin{array}{l}\text { Scheer and Pillai } \\
(1983)\end{array}$ & $\begin{array}{l}\text { Sheppard and Sheppard } \\
\text { (1991) }\end{array}$ & $\begin{array}{l}\text { Veron } \\
(2000)\end{array}$ & $\begin{array}{l}\text { This } \\
\text { study }\end{array}$ \\
\hline $\begin{array}{l}\text { Gardineroseris } \\
\text { planulata }\end{array}$ & $\mathrm{x}$ & $\mathrm{x}$ & $\mathrm{x}$ & $\mathrm{x}$ \\
\hline Pavona cactus & $\mathrm{x}$ & $\mathrm{x}$ & $\mathrm{x}$ & $\mathrm{x}$ \\
\hline Pavona clavus & & & $\mathrm{x}$ & $\mathrm{x}$ \\
\hline Pavona danai & & & $\mathrm{x}$ & $\mathrm{x}$ \\
\hline Pavona decussata & $\mathrm{x}$ & $\mathrm{x}$ & $\mathrm{x}$ & $\mathrm{x}$ \\
\hline Pavona diffluens & & $\mathrm{x}$ & $\mathrm{x}$ & $\mathrm{x}$ \\
\hline Pavona divaricata & $\mathrm{x}$ & & & \\
\hline Pavona duerdeni & & $\mathrm{x}$ & $\mathrm{x}$ & \\
\hline Pavona explanulata & $\mathrm{x}$ & $\mathrm{x}$ & $\mathrm{x}$ & $\mathrm{x}$ \\
\hline Pavona frondifera & & & $\mathrm{x}$ & $\mathrm{x}$ \\
\hline Pavona maldivensis & $\mathrm{x}$ & $\mathrm{x}$ & $\mathrm{x}$ & $\mathrm{x}$ \\
\hline Pavona minuta & & $\mathrm{x}$ & & \\
\hline Pavona varians & $\mathrm{x}$ & $\mathrm{x}$ & $\mathrm{x}$ & $\mathrm{x}$ \\
\hline Pavona venosa & & $\mathrm{x}$ & $\mathrm{x}$ & $\mathrm{x}$ \\
\hline Leptoseris explanata & $\mathrm{x}$ & $\mathrm{x}$ & $\mathrm{x}$ & $\mathrm{x}$ \\
\hline Leptoseris foliosa & & $\mathrm{x}$ & $\mathrm{x}$ & \\
\hline Leptoseris fragilis & $\mathrm{x}$ & & & $\mathrm{x}$ \\
\hline Leptoseris gardineri & $\mathrm{x}$ & & & \\
\hline Leptoseris glabra & & & & $\mathrm{x}$ \\
\hline Leptoseris hawaiiensis & $\mathrm{x}$ & $\mathrm{x}$ & $\mathrm{x}$ & $\mathrm{x}^{*}$ \\
\hline Leptoseris incrustans & & & $\mathrm{x}$ & $\mathrm{x}$ \\
\hline $\begin{array}{l}\text { Leptoseris } \\
\quad \text { mycetoseroides }\end{array}$ & & $\mathrm{x}$ & $\mathrm{x}$ & $\mathrm{x}$ \\
\hline Leptoseris scabra & $\mathrm{x}$ & $\mathrm{x}$ & $\mathrm{x}$ & $\mathrm{x}$ \\
\hline Leptoseris tenuis & $\mathrm{x}$ & & & \\
\hline Leptoseris yabei & $\mathrm{x}$ & $\mathrm{x}$ & $\mathrm{x}$ & $\mathrm{x}$ \\
\hline Total & 14 & 16 & 19 & 18 \\
\hline
\end{tabular}

*Recorded as Leptoseris cf. hawaiiensis transcribed spacer 1 from nuclear ribosomal DNA (ITS1), were sequenced to define morphospecies monophyly and relationships. This study represents the first molecular phylogeny of Agariciidae from the RS, and in general from the IO, and will allow the comparison of agariciid genetic diversity and connectivity of the RS to other localities of the IndoPacific. The results highlight a disagreement between our identifications based on classical morphologic characters and DNA for most species, suggesting the need to include more locations, variable loci, and the integration of micromorphological data to disentangle the systematics of this group.

\section{Materials and methods}

\section{Sampling}

Between 2012 and 2016, 91 samples belonging to the family Agariciidae were collected from several localities along the
Saudi Arabian RS coast, from the GofA to the Farasan Islands (Table 1). Prior to collection, living coral colonies were photographed in the field using either a Canon G9 or G11 PowerShot digital camera (Canon Inc., Tokyo, Japan) in an Ikelite underwater housing (Ikelite Underwater Systems, Indianapolis, IN, USA). Specimens were sampled during SCUBA diving between 1 and $30 \mathrm{~m}$ depth using hammer and chisel. A small fragment $\left(<1 \mathrm{~cm}^{2}\right)$ of each coral colony was preserved in $96 \%$ ethanol for molecular analyses. The rest of the corallum was tagged and bleached in sodium hypochlorite for $48 \mathrm{~h}$ in order to remove tissue parts, rinsed with fresh water, and air-dried. Images of cleaned skeletons were taken with a Canon G9 or G11 PowerShot digital camera.

\section{Species identification}

Specimens were identified to the species level based on macromorphological features of the coralla and the corallites. For the genus Leptoseris, we referred to the revision by 
Dinesen (1980), including descriptions and illustrations of type material. For Leptoseris yabei (Pillai \& Scheer, 1976), originally described in Pavona, we referred to the original description and holotype illustration (pl. 16, figs. 1,2) by Pillai and Scheer (1976). For the other genera, Veron and Pichon (1980), Scheer and Pillai (1983), Sheppard and Sheppard (1991), Nishihira and Veron (1995), and Veron (2000) were referenced. The type material of Agariciidae species deposited at the National Museum of Natural History (MNHN), Paris, France and at the Smithsonian Institution, National Museum of Natural History (formerly known as United States National Museum of Natural History) (USNM), Washington, USA, was also examined by FB and imaged. These images were used as reference for the identification of a number of species, namely Leptoseris fragilis Milne Edwards \& Haime, 1849 (MNHN 468), Leptoseris scabra Vaughan, 1907 (USNM 20885; USNM 20886), Leptoseris hawaiiensis Vaughan, 1907 (USNM 20874; USNM 20876), Leptoseris mycetoseroides Wells, 1954 (USNM 44805; USNM 44807), Pavona diffluens (Lamarck, 816) (MNHN IK-2010-587), Pavona danai (USNM 136), Pavona duerdeni Vaughan, 1907 (USNM 21630; USNM 21631), and P. decussata (USNM 176).

\section{DNA extraction, amplification, and sequence analyses}

Genomic DNA was extracted from samples using the commercial DNAeasy ${ }^{\circledR}$ Blood \& Tissue Kit (Qiagen Inc., Hilden, Germany), following the manufacturer's protocol. Primers AGAH and AGAL (Terraneo et al. 2014) were used to amplify IGR locus, while 1S and 2SS primers (Wei et al. 2006) were used to amplify ITS1. All of the polymerase chain reaction (PCR) products were purified with Illustra ExoStar (GE Healthcare, Buckinghamshire, UK) at $37^{\circ}$ for $60 \mathrm{~min}$, followed by $85^{\circ}$ for $15 \mathrm{~min}$, and sent for direct sequencing in both forward and reverse directions using an ABI 3730xl DNA analyzer (Applied Biosystems, Carlsbad, CA, USA). All the sequences generated from this work were deposited in EMBL (Table 1).

Forward and reverse sequences were viewed, edited, and assembled using Sequencher 5.3 (Gene Codes Corp., Ann Arbor, MI, USA). Nuclear sequences were phased using SeqPHASE (Flot 2010; available online at http://seqphase. mpg.de/seqphase/) and PHASE was used (Stephens et al. 2001; available online at http://stephenslab.uchicago.edu/ software.html) when alleles showed the same length; Champuru (Flot 2007; available online at http://seqphase.mpg. de/champuru/) was used if the two predominant alleles were of different lengths. In the former case, the two alleles with the highest probability (an order of magnitude greater than the other sequence pairs) were chosen whenever there were multiple possible phases. No obvious or significant differences of genetic diversity and haploweb inference were obtained using alternative phases (results not shown). Phased heterozygotes were represented by both alleles in the further alignments and population genetic analyses. Final alignments were performed using the E-INS-i option in MAFFT 7.130b (Katoh and Standley 2013) under default parameters and manually checked using BioEdit 7.2.5 (Hall 1999). Ambiguously aligned regions were removed from the alignments using Gblocks $0.91 \mathrm{~b}$ (Castresana 2000) using the "more stringent" selection (alignment data are available from the corresponding author upon request). Invariable, polymorphic, and parsimony-informative sites were detected using DnaSP 5.10.01 (Librado and Rozas 2009).

The two loci were analyzed separately, and phylogenetic relationships between species were assessed using Bayesian inference (BI), maximum likelihood (ML), and maximum parsimony (MP), as implemented in MrBayes 3.1.2 (Ronquist and Huelsenbeck 2003), PhyML 3.0 (Guindon and Gascuel 2003), and PAUP* 4.0b10 (Swofford 2002), respectively. We used the Akaike information criterion (AIC) implemented in MrModeltest 2.3 (Posada and Crandall 1998) in conjunction with PAUP* $4.0 \mathrm{~b} 10$ to determine the best-fit substitution model of sequence evolution. The AIC selected the General Time Reversible (GTR) + invariable sites + gamma model of nucleotide substitution for both markers (Pinv $=0.28, \alpha=0.51$ for IGR, and Pinv $=0.78, \alpha=0.55$ for ITS1). The BI analysis consisted of four independent Markov chain Monte Carlo (MCMC) runs for 6,000,000 generations for IGR $(10,000,000$ for ITS1), saving a tree every 1000 generations and discarding the first $25 \%$ of the trees as burn-in, on the basis of parameter estimations and convergence examined by Tracer 1.6 (Rambaut and Drummond 2007). Clade support was based on posterior probability. The ML analysis was run using the default parameters, the previously selected model, and 1000 bootstrap replicates to verify the robustness of the internal branches of the tree. For MP, a heuristic search was performed using starting trees obtained by random stepwise addition with 10 replicates and the tree bisection and reconnection (TBR) branch-swapping-algorithm, generating a strict consensus tree. The robustness of the internal branches of the tree was verified using 1000 bootstrap replicates. The two alignments and phylogenetic trees are available in TreeBASE (http://purl.org/ phylo/treebase/phylows/study/TB2:S20870).

\section{Results}

The 91 Agariciidae colonies collected in the Saudi Arabian RS were identified based on colony and corallite macromorphology, amounting to a total of 20 species ascribed to three genera, namely Pavona, Leptoseris, and Gardineroseris (Table 1) (Figs. 1 and 2). One Leptoseris specimen was identified as Leptoseris cf. hawaiiensis. The uncertainty about the identification of this distinct specimen stems from the substantial morphological differences between the actual type material and 
Fig. 1 In vivo colony morphology of the Agariciidae collected for this study in the Saudi Arabian Red Sea (RS): a SA0076 Pavona venosa; b SA0857 Pavona varians; c SA0368 Pavona maldivensis; d SA0105 Leptoseris fragilis; e SA0269 Pavona decussata; f SA0810 Gardineroseris planulata; g SA0369 Pavona clavus; h SA0943 Leptoseris sp.; i SA0942 Pavona explanulata; j SA0781 Leptoseris

mycetoseroides; $\mathbf{k} \mathrm{SA} 0884$ Leptoseris cf. hawaiiensis; 1 SA2654 Leptoseris scabra; m SA2608 Leptoseris incrustans; $\mathbf{n}$ SA0097 Leptoseris explanata; 0 SA0893 Pavona diffluens; $\mathbf{p}$ SA0088 Leptoseris glabra; $\mathbf{q}$ SA0424 Leptoseris yabei; $\mathbf{r}$ SA0052 Pavona danae; $\mathbf{s}$ SA0205 Pavona cactus; $\mathbf{t}$ SA2653 Pavona frondifera

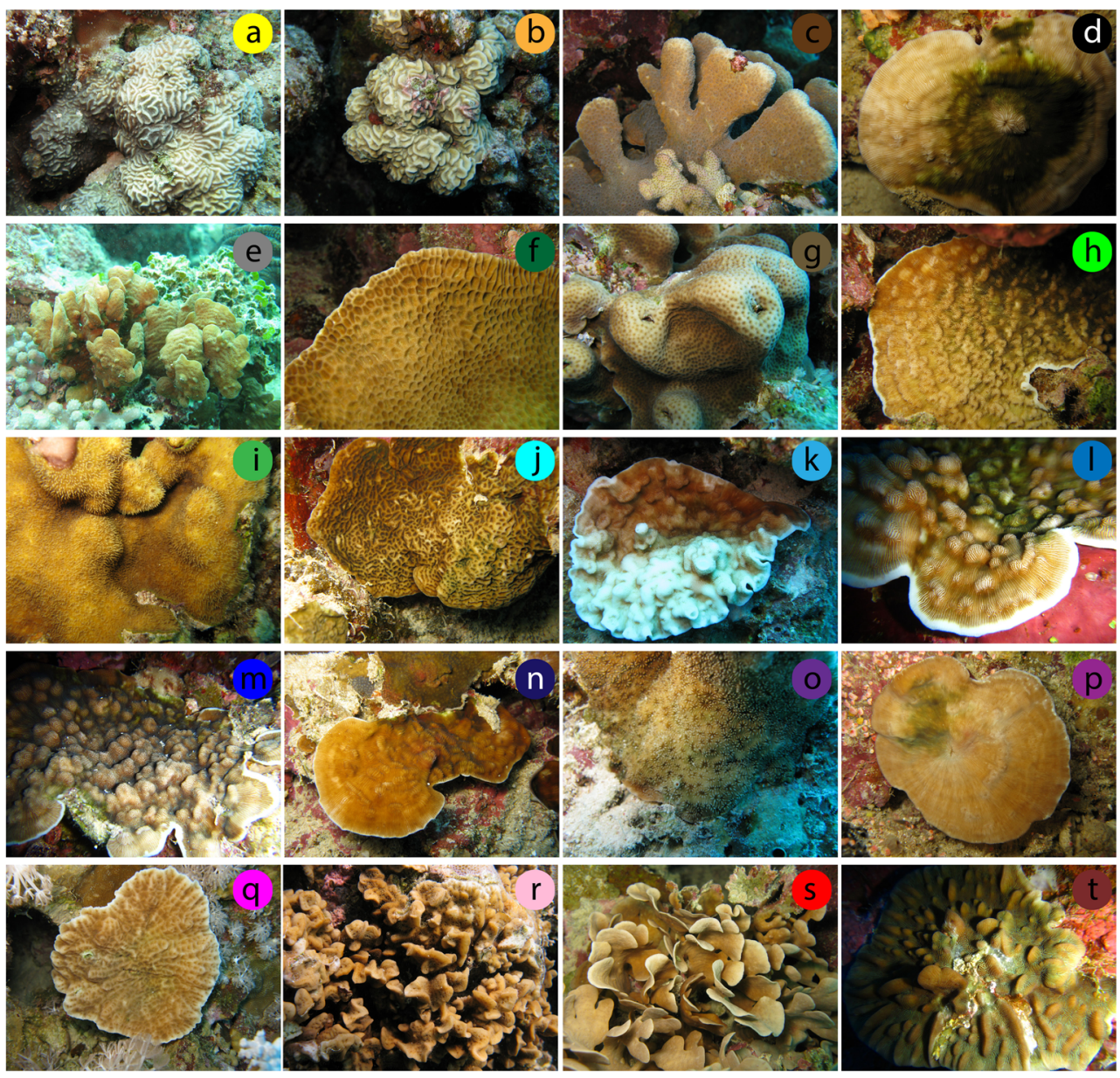

specimens and colonies identified by other authors as L. hawaiiensis (Sheppard and Sheppard 1991; Veron 2000).

\section{Phylogenetic analyses}

The final mitochondrial alignment consisted of $1081 \mathrm{bp}$ and included 187 polymorphic sites (71 of which were singleton sites) and 116 parsimony-informative sites. Two hundred and fifty-seven mutations were recovered from the dataset when evaluating synonymous and nonsynonymous substitutions. The ITS alignment consisted of $468 \mathrm{bp}$ and 54 polymorphic sites (14 of which were 14 singleton sites), 40 parsimony-informative sites, and a total of 49 mutations.

Two sequences of Siderastrea radians (Pallas, 1776) were downloaded from GenBank and used as the outgroup for both mitochondrial and nuclear datasets because of the known divergence of this species from Agariciidae (Fukami et al. 2008; Luck et al. 2013; Terraneo et al. 2014; Pochon et al. 2015). Topologies derived from BI, ML, and MP were mostly in agreement, resolving the same well-supported molecular clades without any conflicting partition. In Figs. 3 and 4, we report the Bayesian phylogram with branch support indicated by Bayesian posterior probability $\left(\mathrm{BB}_{\mathrm{PI}}\right), \mathrm{ML}$ bootstrapping support $\left(\mathrm{BT}_{\mathrm{ML}}\right)$, and $\mathrm{MP}$ bootstrapping support $\left(\mathrm{BT}_{\mathrm{MP}}\right)$.

The mitochondrial phylogenetic reconstruction demonstrates that genus-level boundaries of Leptoseris, Pavona, and Gardineroseris are not genetically supported (Fig. 3). In fact, Leptoseris and Pavona as currently defined are intermixed between each other, and the monotypic genus Gardineroseris nests together with Leptoseris and Pavona.

According to the mitochondrial reconstruction, species-level boundaries are also unclear for many of the analyzed taxa. Gardineroseris planulata forms a monophyletic group (CLADE V) strongly supported by the three analysis criteria (0.94/100/100). Similarly, Leptoseris fragilis (CLADE III), L. yabei (CLADE XIII), and Leptoseris sp. (CLADE VII) are monophyletic and grouped in highly supported clades (node values $1 / 100 / 100,0.99 /-/ 100$, and 1/99/100, respectively). Sequences of $L$. mycetoseroides are split into two distinct clades (CLADE IX and CLADE XI), showing cryptic genetic divergence within the morphospecies. Leptoseris cf. hawaiiensis, L. scabra, L. incrustans, L. explanata, and L. glabra are genetically indistinguishable based on this marker and grouped together in CLADE XII, which also includes all the analyzed samples of P. diffluens. Pavona maldivensis (CLADE II) forms 
Fig. 2 Skeletal macromorphology of the Agariciidae species collected for this study in the Saudi Arabian Red Sea (RS): a SA0076 Pavona venosa; b SA0857 Pavona varians; c SA0368 Pavona maldivensis; d SA0105 Leptoseris fragilis; e SA0269 Pavona decussata; f SA0810 Gardineroseris planulata; $\mathbf{g}$ SA0369 Pavona clavus; $\mathbf{h}$ SA0943 Leptoseris sp.; i SA0942 Pavona explanulata; j SA0781 Leptoseris mycetoseroides; $\mathbf{k}$ SA0884 Leptoseris cf. hawaiiensis; I SA2654 Leptoseris scabra; m SA2608 Leptoseris incrustans; n SA0097 Leptoseris explanata; o SA0893 Pavona diffluens; p SA0088 Leptoseris glabra; q SA0424 Leptoseris yabei; r SA0052 Pavona danae; $\mathbf{s}$ SA0205 Pavona cactus; $\mathbf{t}$ SA2653 Pavona frondifera

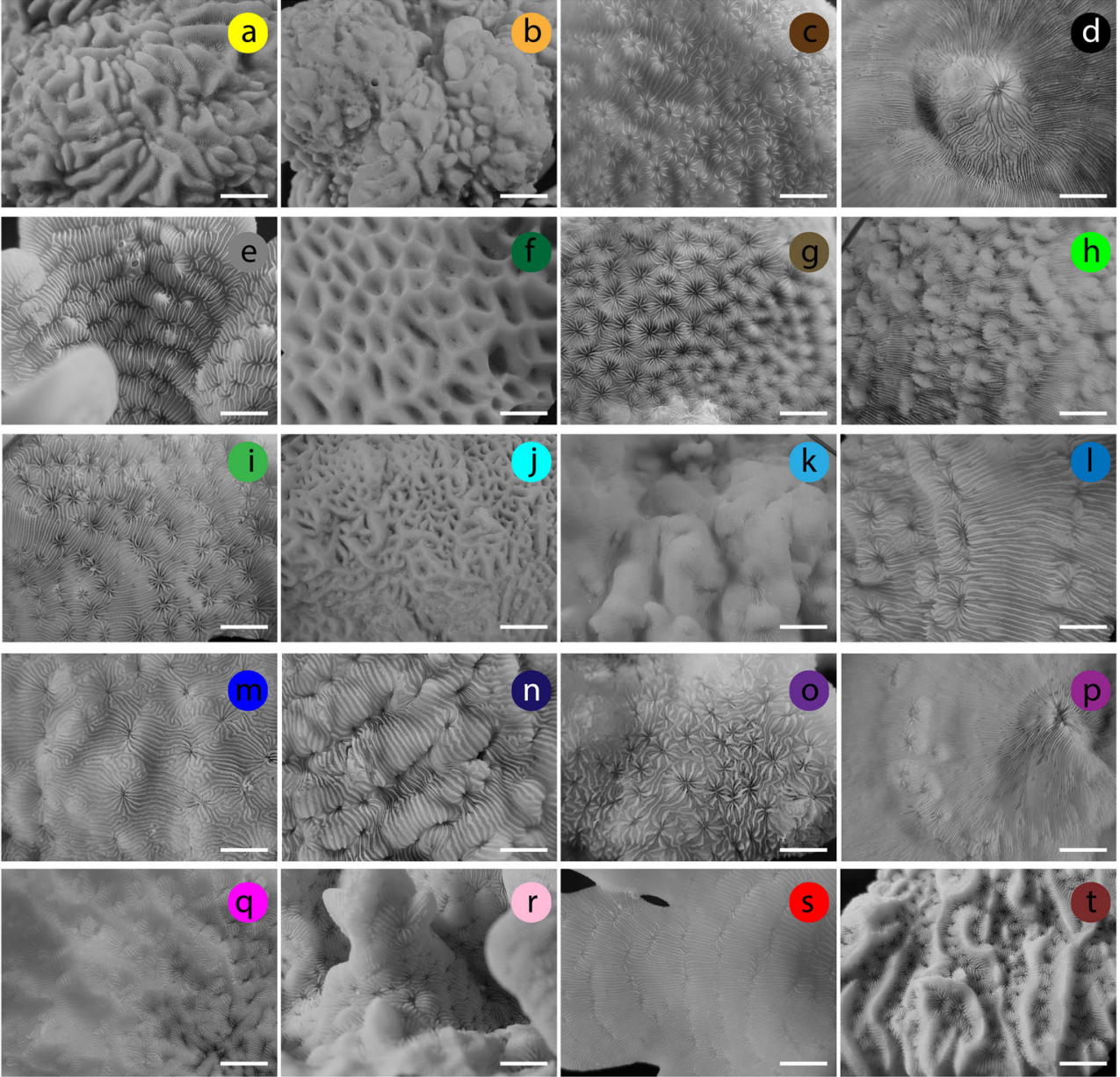

a monophyletic group strongly supported by the three phylogenetic analyses $(0.98 / 96 / 84)$. All representatives of $P$. decussata (CLADE IV) cluster together in a highly supported lineage $(1 / 100 / 100)$. The only examined sample of $P$. clavus is highly divergent within the tree (CLADE VI), but one specimen is not sufficient to evaluate its monophyly. Based on mitochondrial sequence data, $P$. venosa and $P$. varians are indistinguishable from a molecular point of view, and are nested together in CLADE I, while $P$. explanulata is comprised of two distinct lineages (CLADE VIII and CLADE X). Finally, the frondose Pavona danai Milne Edwards, 1860, Pavona frondifera (Lamarck, 1816), and P. cactus form a single clade (CLADE XIV) basal to the entire phylogeny (Fig. 3, Table 3).

The phylogenetic tree based on nuclear ITS1 is less resolved than the mitochondrial phylogeny reconstruction, though no contrasting patterns are found between the two analyses, supporting the stability of relationships among species. All agariciids form an unresolved clade due to a large basal polytomy. Similar to the IGR tree topology, Leptoseris, Pavona, and Gardineroseris are closely related and nest together based on ITS1 (Fig. 4), which raises questions regarding the validity of these three genera. Five molecular clades identified by IGR are also resolved in the ITS1 phylogeny, including
P. maldivensis (CLADE II), G. planulata (CLADE V), P. clavus (CLADE VI), L. yabei (CLADE XIII), and P. danai, $P$. frondifera, and $P$. cactus (CLADE XIV). Pavona decussata (CLADE IV) and $P$. varians and $P$. venosa (CLADE I) group together in a molecular lineage $(-/ 79 /-)$ and, interestingly, representatives of $P$. decussata form a group genetically isolated from the other two species. Leptoseris fragilis (CLADE III) and Leptoseris sp. (CLADE VII) are unresolved, forming part of the large basal polytomy, but they do not cluster with any other morphospecies. Leptoseris mycetoseroides (CLADES IX and $\mathrm{XI}$ ) is unresolved and representatives of these two clades are mixed together. Similar to the placement of $L$. mycetoseroides, $P$. explanulata (CLADES VIII and X) is also unresolved, though sequences ascribed to these two clades mix together. Lastly, P. diffluens, L. explanata, L. glabra, L. incrustans, and L. scabra (CLADE XII) are unresolved in the large basal polytomy of the ITS1 phylogenetic tree.

\section{Discussion}

In the present study, we provide a preliminary genetic survey of the scleractinian coral family Agariciidae from the Saudi 


$\square$ P. venosa
$\square$ P. varians
$\square$ P. maldivensis
$\square$ L. fragilis
$\square$ P. decussata
$\square$ G. planulata
$\square$ P. clavus
$\square$ L. sp
$\square$ P. explanulata
$\square$ L. mycetoseroides
$\square$ L. cf hawaiiensis
$\square$ L. scabra
$\square$ L. incrustans
$\square$ L. explanata
$\square$ P. diffluens
$\square$ L. glabra
$\square$ L. yabei
$\square$ P. danai
$\square$ P. cactus
$\square$ P. frondifera

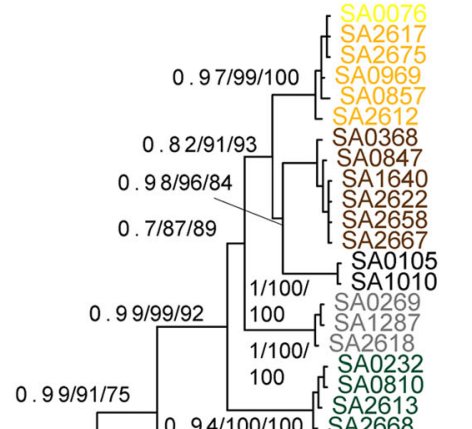

$P$. venosa

clade I

$P$. varians

P. maldivensis

clade II

L. fragilis

clade III

P. decussata

clade IV

G. planulata

clade V

$P$. clavus

clade VI

L. $\mathrm{sp}$

clade VII

P. explanulata

clade VIII

L. mycetoseroides

clade IX

$P$. explanulata

clade X

L. mycetoseroides

clade XI

100

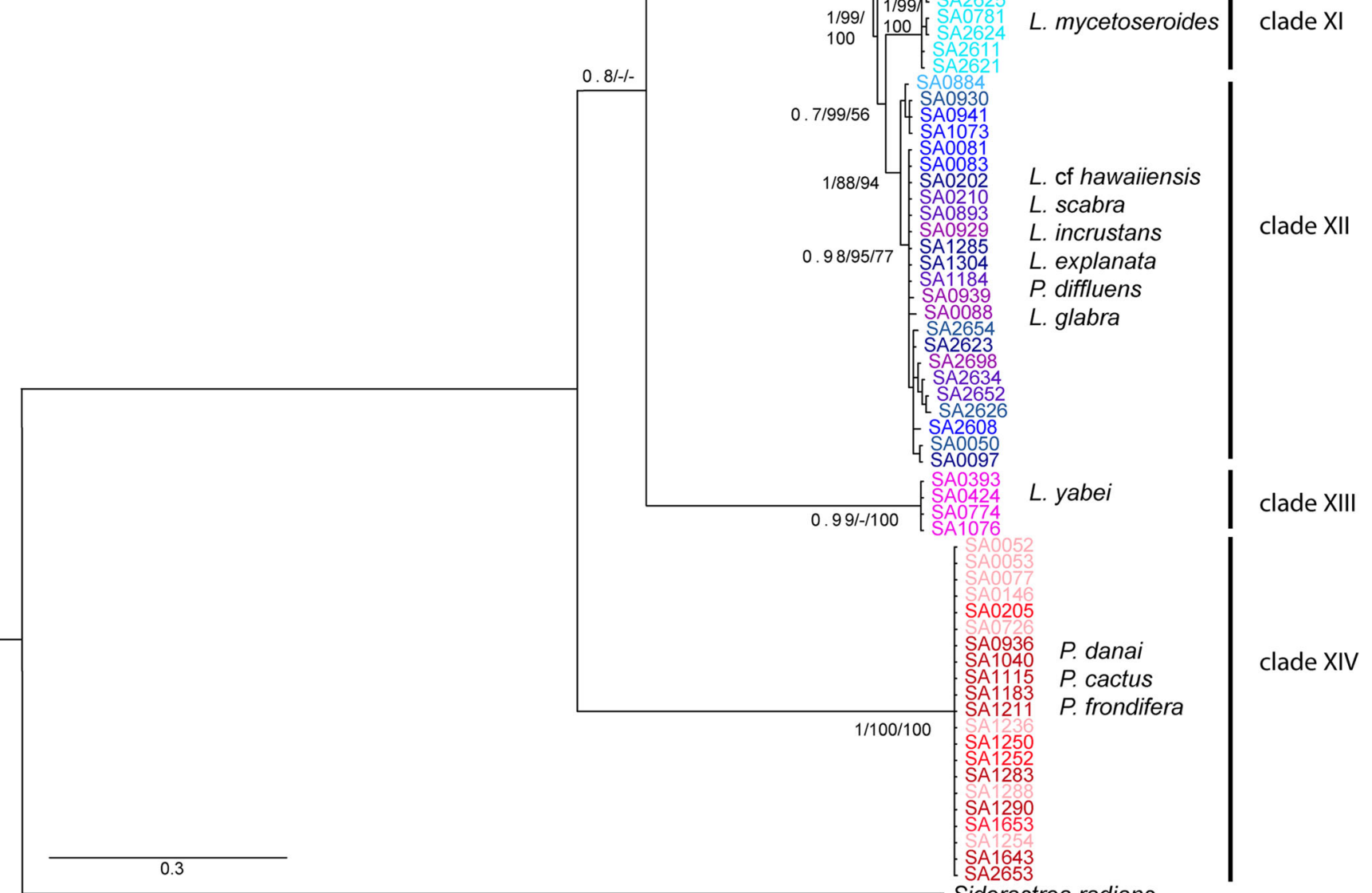

Fig. 3 Phylogenetic reconstruction of the family Agariciidae from the Saudi Arabian Red Sea (RS) inferred from Bayesian inference (BI) analysis of the mitochondrial intergenic spacer between COI and 16S rRNA (IGR). All the different morphospecies are color coded. Node values are posterior Bayesian probabilities, maximum likelihood (ML) bootstrap

Arabian RS. After intensive sampling over $1200 \mathrm{~km}$ from the GofA in the north to the Farasan Islands in the south, we recorded a total of 20 agariciid morphospecies belonging to the genera values, and maximum parsimony (MP) bootstrap values. Posterior Bayesian probabilities below 0.7, ML bootstrap values below 50\%, and MP bootstrap values below $50 \%$ are indicated by a dash (-). Siderastrea radians was selected as the outgroup

Gardineroseris, Leptoseris, and Pavona (Table 2). Taxa were investigated at two molecular regions: the mitochondrial IGR and the nuclear ITS1. The resulting phylogenetic reconstructions 


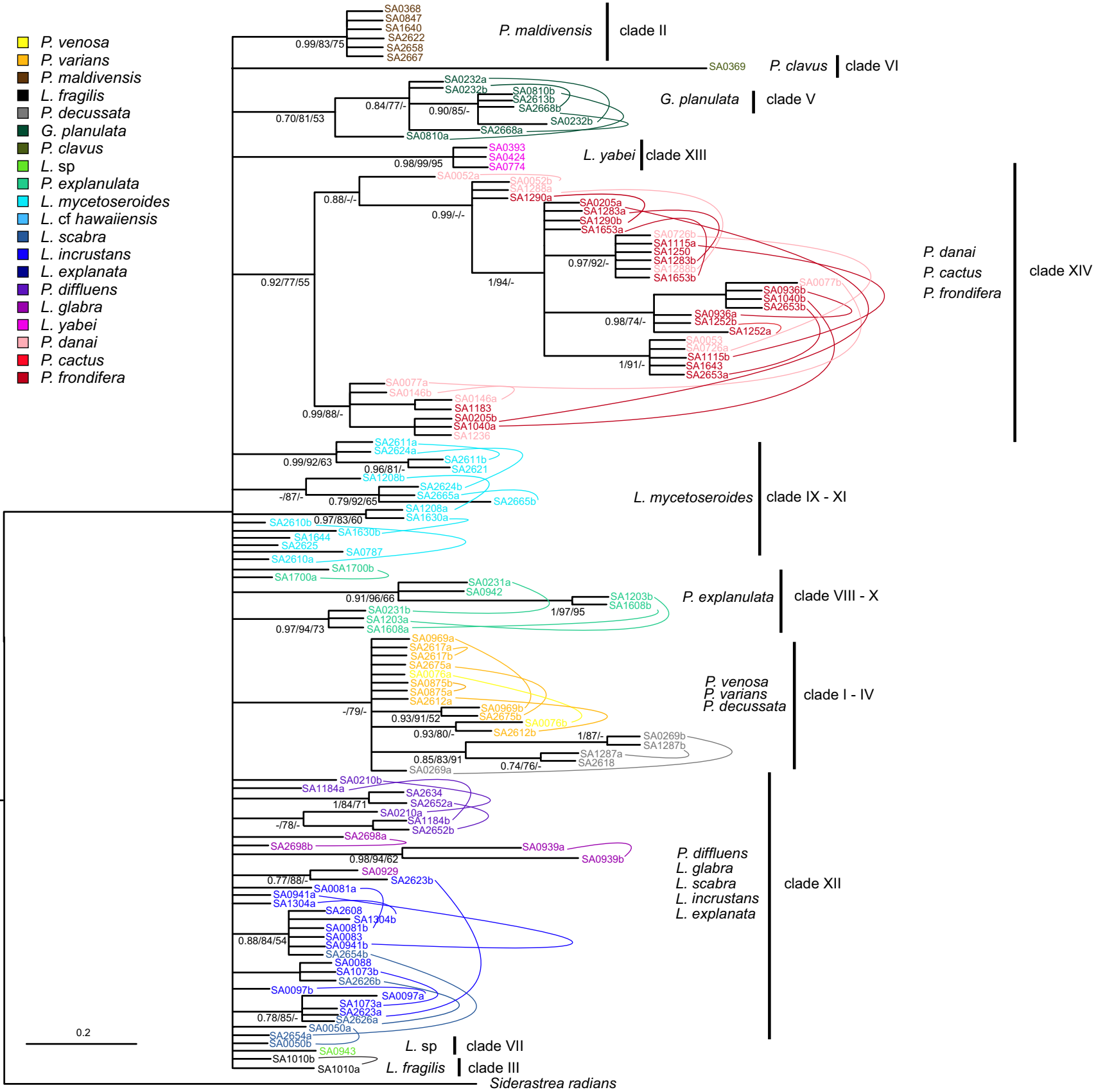

Fig. 4 Phylogenetic reconstruction of the family Agariciidae from the Saudi Arabian Red Sea (RS) inferred from Bayesian inference (BI) analysis of the internal transcribed spacer 1 from nuclear ribosomal DNA (ITS1). All the different morphospecies are color coded as in Fig. 3. Node values are posterior Bayesian probabilities, maximum likelihood
(ML) bootstrap values, and maximum parsimony (MP) bootstrap values. Posterior Bayesian probabilities below 0.7, ML bootstrap values below $50 \%$, and MP bootstrap values below $50 \%$ are indicated by a dash $(-)$. Siderastrea radians was selected as the outgroup

$P$. cactus and $P$. decussata from Mauritius. Additionally, seven species (P. venosa, P. danai, P. diffluens, L. fragilis, L. explanata, L. glabra, and L. yabei) were included in a molecular phylogenetic study for the first time in this study.

The morphospecies diversity that we reported from the Saudi Arabian RS is compatible with that reported in previous works from the region (Scheer and Pillai 1983; Sheppard and Sheppard 1991; Veron 2000), though with some distinct 
Table 2 List of samples analyzed in the present study

\begin{tabular}{|c|c|c|c|c|c|c|c|}
\hline Code & Identification & Collector & Locality & Latitude & Longitude & IGR & ITS1 \\
\hline SA0050 & Leptoseris scabra & FB & Dolphen Lagoon, Farasan Banks & $19^{\circ} 00.320^{\prime}$ & $40^{\circ} 08.889^{\prime}$ & LT630767 & LT630858-9 \\
\hline SA0052 & Pavona danae & FB & Dolphen Lagoon, Farasan Banks & $19^{\circ} 00.320^{\prime \prime}$ & $40^{\circ} 08.889^{\prime}$ & LT630768 & LT630860-1 \\
\hline SA0053 & Pavona danae & FB & Dolphen Lagoon, Farasan Banks & $19^{\circ} 00.320^{\prime}$ & $40^{\circ} 08.889^{\prime}$ & LT630769 & LT630862 \\
\hline SA0076 & Pavona venosa & FB & Ablo Reef, Farasan Banks & $18^{\circ} 39.571^{\prime}$ & $40^{\circ} 49.618^{\prime}$ & LT630770 & LT630863-4 \\
\hline SA0077 & Pavona danae & FB & Ablo Reef, Farasan Banks & $18^{\circ} 39.571^{\prime}$ & $40^{\circ} 49.618^{\prime}$ & LT630771 & LT630865-6 \\
\hline SA0081 & Leptoseris incrustans & FB & Ablo Reef, Farasan Banks & $18^{\circ} 39.571^{\prime}$ & $40^{\circ} 49.618^{\prime}$ & LT630772 & LT630867-8 \\
\hline SA0083 & Leptoseris incrustans & FB & Ablo Reef, Farasan Banks & $18^{\circ} 39.571^{\prime}$ & $40^{\circ} 49.618^{\prime}$ & LT630773 & LT630869 \\
\hline SA0088 & Leptoseris glabra & FB & Ablo Reef, Farasan Banks & $18^{\circ} 39.571^{\prime}$ & $40^{\circ} 49.618^{\prime}$ & LT630774 & LT630870 \\
\hline SA0097 & Leptoseris explanata & FB & Ablo Reef, Farasan Banks & $18^{\circ} 39.571^{\prime}$ & $40^{\circ} 49.618^{\prime}$ & LT630775 & LT630871-2 \\
\hline SA0105 & Leptoseris fragilis & FB & Ablo Reef, Farasan Banks & $18^{\circ} 39.571^{\prime}$ & $40^{\circ} 49.618^{\prime}$ & LT630776 & - \\
\hline SA0146 & Pavona danae & FB & Marka Reef, Farasan Banks & $18^{\circ} 13.233^{\prime}$ & $41^{\circ} 19.463^{\prime}$ & LT630777 & LT630873-4 \\
\hline SA0202 & Leptoseris explanata & FB & Marka Reef, Farasan Banks & $18^{\circ} 13.233^{\prime}$ & $41^{\circ} 19.463^{\prime}$ & LT630778 & - \\
\hline SA0205 & Pavona cactus & FB & Marka Reef, Farasan Banks & $18^{\circ} 13.233^{\prime}$ & $41^{\circ} 19.463^{\prime}$ & LT630779 & LT630875-6 \\
\hline SA0210 & Pavona diffluens & FB & Marka Reef, Farasan Banks & $18^{\circ} 13.233^{\prime}$ & $41^{\circ} 19.463^{\prime}$ & LT630780 & LT630877-8 \\
\hline SA0231 & Pavona explanulata & FB & Shi'b Rabid, Farasan Banks & $18^{\circ} 04.385^{\prime}$ & $40^{\circ} 53.154^{\prime}$ & LT630781 & LT630879-80 \\
\hline SA0232 & Gardineroseris planulata & FB & Shi'b Rabid, Farasan Banks & $18^{\circ} 04.385^{\prime}$ & $40^{\circ} 53.154^{\prime}$ & LT630782 & LT630881-2 \\
\hline SA0269 & Pavona decussata & FB & Shuma North, Farasan Banks & $16^{\circ} 45.159^{\prime}$ & $41^{\circ} 36.297^{\prime}$ & LT630783 & LT630883-4 \\
\hline SA0368 & Pavona maldivensis & FB & Shi’b Nazar, Thuwal & $16^{\circ} 45.159^{\prime}$ & $41^{\circ} 36.297^{\prime}$ & LT630784 & LT630885 \\
\hline SA0369 & Pavona clavus & FB & Shi'b Nazar, Thuwal & $16^{\circ} 45.159^{\prime}$ & $41^{\circ} 36.297^{\prime}$ & LT630785 & LT630886 \\
\hline SA0393 & Leptoseris yabei & FB & Palace Reef, Thuwal & $22^{\circ} 18.256^{\prime}$ & $38^{\circ} 57.505^{\prime}$ & LT630786 & LT630887 \\
\hline SA0424 & Leptoseris yabei & FB & Qita Al Kirsh, Thuwal & $22^{\circ} 25.358^{\prime}$ & $38^{\circ} 59.461^{\prime}$ & LT630787 & LT630888 \\
\hline SA0676 & Leptoseris mycetoseroides & FB & Al Wajh & $25^{\circ} 23.515^{\prime}$ & $36^{\circ} 41.035^{\prime}$ & LT630788 & - \\
\hline SA0726 & Pavona danae & FB & Ras Al-Ubayd & $26^{\circ} 44.167^{\prime}$ & $36^{\circ} 02.659^{\prime}$ & LT630789 & LT630889-90 \\
\hline SA0774 & Leptoseris yabei & FB & Jaz'air Silah & $27^{\circ} 38.302^{\prime}$ & $35^{\circ} 18.369^{\prime}$ & LT630790 & LT630891 \\
\hline SA0781 & Leptoseris mycetoseroides & FB & Jaz'air Silah & $27^{\circ} 38.302^{\prime}$ & $35^{\circ} 18.369^{\prime}$ & LT630791 & - \\
\hline SA0787 & Leptoseris mycetoseroides & FB & Jaz'air Silah & $27^{\circ} 38.302^{\prime}$ & $35^{\circ} 18.369^{\prime}$ & LT630792 & LT630892 \\
\hline SA0810 & Gardineroseris planulata & FB & Jaz'air Silah & $27^{\circ} 38.302^{\prime}$ & $35^{\circ} 18.369^{\prime}$ & LT630793 & LT630893-4 \\
\hline SA0847 & Pavona maldivensis & FB & Jazirat Burcan & $27^{\circ} 49.003^{\prime}$ & $35^{\circ} 06.397^{\prime}$ & LT630794 & LT630895 \\
\hline SA0857 & Pavona varians & FB & Jazirat Burcan & $27^{\circ} 49.003^{\prime}$ & $35^{\circ} 06.397^{\prime}$ & LT630795 & LT630896-7 \\
\hline SA0884 & Leptoseris cf. hawaiiensis & FB & Jazirat Burcan & $27^{\circ} 49.003^{\prime}$ & $35^{\circ} 06.397^{\prime}$ & LT630796 & - \\
\hline SA0893 & Pavona diffluens & FB & Jazirat Burcan & $27^{\circ} 49.003^{\prime}$ & $35^{\circ} 06.397^{\prime}$ & LT630797 & - \\
\hline SA0929 & Leptoseris glabra & FB & Magna Coast Guard, Gulf of Aqaba & $28^{\circ} 24.232^{\prime}$ & $34^{\circ} 44.440^{\prime}$ & LT630798 & LT630898 \\
\hline SA0930 & Leptoseris scabra & FB & Magna Coast Guard, Gulf of Aqaba & $28^{\circ} 24.232^{\prime}$ & $34^{\circ} 44.440^{\prime}$ & LT630799 & - \\
\hline SA0936 & Pavona frondifera & FB & Magna Coast Guard, Gulf of Aqaba & $28^{\circ} 24.232^{\prime}$ & $34^{\circ} 44.440^{\prime}$ & LT630800 & LT630899-900 \\
\hline SA0939 & Leptoseris glabra & FB & Magna Coast Guard, Gulf of Aqaba & $28^{\circ} 24.232^{\prime}$ & $34^{\circ} 44.440^{\prime}$ & LT630801 & LT630901-2 \\
\hline SA0941 & Leptoseris incrustans & FB & Magna Coast Guard, Gulf of Aqaba & $28^{\circ} 24.232^{\prime}$ & $34^{\circ} 44.440^{\prime}$ & LT630802 & LT630903-4 \\
\hline SA0942 & Pavona explanulata & FB & Magna Coast Guard, Gulf of Aqaba & $28^{\circ} 24.232^{\prime}$ & $34^{\circ} 44.440^{\prime}$ & LT630803 & LT630905 \\
\hline SA0943 & Leptoseris sp & FB & Magna Coast Guard, Gulf of Aqaba & $28^{\circ} 24.232^{\prime}$ & $34^{\circ} 44.440^{\prime}$ & LT630804 & LT630906 \\
\hline SA0967 & Leptoseris sp & FB & Magna Coast Guard, Gulf of Aqaba & $28^{\circ} 24.232^{\prime}$ & $34^{\circ} 44.440^{\prime}$ & LT630805 & - \\
\hline SA0969 & Pavona varians & FB & Magna Coast Guard, Gulf of Aqaba & $28^{\circ} 24.232^{\prime}$ & $34^{\circ} 44.440^{\prime}$ & LT630806 & LT630907-8 \\
\hline SA1010 & Leptoseris fragilis & FB & Magna Coast Guard, Gulf of Aqaba & $28^{\circ} 24.232^{\prime}$ & $34^{\circ} 44.440^{\prime}$ & LT630807 & LT630909-10 \\
\hline SA1040 & Pavona frondifera & FB & Magna Coast Guard, Gulf of Aqaba & $28^{\circ} 24.232^{\prime}$ & $34^{\circ} 44.440^{\prime}$ & LT630808 & LT630911-2 \\
\hline SA1073 & Leptoseris incrustans & FB & Ship Wreck Bay, Gulf of Aqaba & $28^{\circ} 11.077^{\prime}$ & $34^{\circ} 38.287^{\prime}$ & LT630809 & LT630913-4 \\
\hline SA1076 & Leptoseris yabei & FB & Ship Wreck Bay, Gulf of Aqaba & $28^{\circ} 11.077^{\prime}$ & $34^{\circ} 38.287^{\prime}$ & LT630810 & - \\
\hline SA1115 & Pavona frondifera & FB & Al Wajh & $25^{\circ} 21.694^{\prime}$ & $36^{\circ} 54.754^{\prime}$ & LT630811 & LT630915-6 \\
\hline SA1183 & Pavona frondifera & FB & Shark Reef, Thuwal & $22^{\circ} 25.543^{\prime}$ & $38^{\circ} 59.348^{\prime}$ & LT630812 & LT630917 \\
\hline SA1184 & Pavona diffluens & FB & Shark Reef, Thuwal & $22^{\circ} 25.543^{\prime}$ & $38^{\circ} 59.348^{\prime}$ & LT630813 & LT630918-9 \\
\hline SA1203 & Pavona explanulata & FB & Shark Reef, Thuwal & $22^{\circ} 25.543^{\prime}$ & $38^{\circ} 59.348^{\prime}$ & LT630814 & LT630920-1 \\
\hline SA1208 & Leptoseris mycetoseroides & FB & Shark Reef, Thuwal & $22^{\circ} 25.543^{\prime}$ & $38^{\circ} 59.348^{\prime}$ & LT630815 & LT630922-3 \\
\hline
\end{tabular}


Table 2 (continued)

\begin{tabular}{|c|c|c|c|c|c|c|c|}
\hline Code & Identification & Collector & Locality & Latitude & Longitude & IGR & ITS1 \\
\hline SA1211 & Pavona frondifera & FB & Shark Reef, Thuwal & $22^{\circ} 25.543^{\prime}$ & $38^{\circ} 59.348^{\prime}$ & LT630816 & - \\
\hline SA1236 & Pavona danae & FB & Shark Reef, Thuwal & $22^{\circ} 25.543^{\prime}$ & $38^{\circ} 59.348^{\prime}$ & LT630817 & LT630924 \\
\hline SA1250 & Pavona cactus & FB & Shark Reef, Thuwal & $22^{\circ} 25.543^{\prime}$ & $38^{\circ} 59.348^{\prime}$ & LT630818 & LT630925 \\
\hline SA1252 & Pavona cactus & FB & Shark Reef, Thuwal & $22^{\circ} 25.543^{\prime}$ & $38^{\circ} 59.348^{\prime}$ & LT630819 & LT630926-7 \\
\hline SA1254 & Pavona danae & FB & Shark Reef, Thuwal & $22^{\circ} 25.543^{\prime}$ & $38^{\circ} 59.348^{\prime}$ & LT630820 & - \\
\hline SA1283 & Pavona frondifera & FB & Shark Reef, Thuwal & $22^{\circ} 25.543^{\prime}$ & $38^{\circ} 59.348^{\prime}$ & LT630821 & LT630928-9 \\
\hline SA1285 & Leptoseris incrustans & FB & Shark Reef, Thuwal & $22^{\circ} 25.543^{\prime}$ & $38^{\circ} 59.348^{\prime}$ & LT630822 & - \\
\hline SA1287 & Pavona decussata & FB & Shark Reef, Thuwal & $22^{\circ} 25.543^{\prime}$ & $38^{\circ} 59.348^{\prime}$ & LT630823 & LT630930-1 \\
\hline SA1288 & Pavona danae & FB & Shark Reef, Thuwal & $22^{\circ} 25.543^{\prime}$ & $38^{\circ} 59.348^{\prime}$ & LT630824 & LT630932-3 \\
\hline SA1290 & Pavona frondifera & FB & Shark Reef, Thuwal & $22^{\circ} 25.543^{\prime}$ & $38^{\circ} 59.348^{\prime}$ & LT630825 & LT630934-5 \\
\hline SA1304 & Leptoseris incrustans & FB & Shark Reef, Thuwal & $22^{\circ} 25.543^{\prime}$ & $38^{\circ} 59.348^{\prime}$ & LT630826 & LT630936-7 \\
\hline SA1608 & Pavona explanulata & FB & Mamali Kebir, Farasan Islands & $17^{\circ} 36.369^{\prime}$ & $41^{\circ} 40.214^{\prime}$ & LT630827 & LT630938-9 \\
\hline SA1630 & Leptoseris mycetoseroides & TIT & Al Baghlah, Farasan Islands & $16^{\circ} 58.734^{\prime}$ & $41^{\circ} 23.094^{\prime}$ & LT630828 & LT630940-1 \\
\hline SA1640 & Pavona maldivensis & FB & Al Baghlah, Farasan Islands & $16^{\circ} 58.734^{\prime}$ & $41^{\circ} 23.094^{\prime}$ & LT630829 & LT630942 \\
\hline SA1643 & Pavona frondifera & FB & Al Baghlah, Farasan Islands & $16^{\circ} 58.734^{\prime}$ & $41^{\circ} 23.094^{\prime}$ & LT630830 & LT630943 \\
\hline SA1644 & Leptoseris mycetoseroides & FB & Al Baghlah, Farasan Islands & $16^{\circ} 58.734^{\prime}$ & $41^{\circ} 23.094^{\prime}$ & LT630831 & LT630944 \\
\hline SA1653 & Pavona cactus & FB & Al Baghlah, Farasan Islands & $16^{\circ} 58.734^{\prime}$ & $41^{\circ} 23.094^{\prime}$ & LT630832 & LT630945-6 \\
\hline SA1700 & Pavona explanulata & FB & Dhi Dahaya, Farasan Islands & $16^{\circ} 52.377^{\prime}$ & $41^{\circ} 26.409^{\prime}$ & LT630833 & LT630947-8 \\
\hline SA2608 & Leptoseris incrustans & MT & Al-Qunfidhah, Farasan Banks & $19^{\circ} 09.483^{\prime}$ & $40^{\circ} 18.065^{\prime}$ & LT630834 & LT630949 \\
\hline SA2610 & Leptoseris mycetoseroides & MT & Al-Qunfidhah, Farasan Banks & $19^{\circ} 09.483^{\prime}$ & $40^{\circ} 18.065^{\prime}$ & LT630835 & LT630950-1 \\
\hline SA2611 & Leptoseris mycetoseroides & MT & Al-Qunfidhah, Farasan Banks & $19^{\circ} 09.483^{\prime}$ & $40^{\circ} 18.065^{\prime}$ & LT630836 & LT630952-3 \\
\hline SA2612 & Pavona varians & MT & Al-Qunfidhah, Farasan Banks & $19^{\circ} 09.483^{\prime}$ & $40^{\circ} 18.065^{\prime}$ & LT630837 & LT630954-5 \\
\hline SA2613 & Gardineroseris planulata & MT & Al-Qunfidhah, Farasan Banks & $19^{\circ} 09.483^{\prime}$ & $40^{\circ} 18.065^{\prime}$ & LT630838 & LT630956-7 \\
\hline SA2617 & Pavona varians & RA & Al-Qunfidhah, Farasan Banks & $19^{\circ} 09.483^{\prime}$ & $40^{\circ} 18.065^{\prime}$ & LT630839 & LT630958-9 \\
\hline SA2618 & Pavona decussata & RA & Al-Qunfidhah, Farasan Banks & $19^{\circ} 09.483^{\prime}$ & $40^{\circ} 18.065^{\prime}$ & LT630840 & LT630960 \\
\hline SA2621 & Leptoseris mycetoseroides & RA & Al-Qunfidhah, Farasan Banks & $19^{\circ} 09.483^{\prime}$ & $40^{\circ} 18.065^{\prime}$ & LT630841 & LT630961 \\
\hline SA2622 & Pavona maldivensis & RA & Al-Qunfidhah, Farasan Banks & $19^{\circ} 09.483^{\prime}$ & $40^{\circ} 18.065^{\prime}$ & LT630842 & LT630962 \\
\hline SA2623 & Leptoseris incrustans & RA & Al-Qunfidhah, Farasan Banks & $19^{\circ} 09.483^{\prime}$ & $40^{\circ} 18.065^{\prime}$ & LT630843 & LT630963-4 \\
\hline SA2624 & Leptoseris mycetoseroides & RA & Al-Qunfidhah, Farasan Banks & $19^{\circ} 09.483^{\prime}$ & $40^{\circ} 18.065^{\prime}$ & LT630844 & LT630965-6 \\
\hline SA2625 & Leptoseris mycetoseroides & RA & Al-Qunfidhah, Farasan Banks & $19^{\circ} 09.483^{\prime}$ & $40^{\circ} 18.065^{\prime}$ & LT630845 & LT630967 \\
\hline SA2626 & Leptoseris scabra & RA & Al-Qunfidhah, Farasan Banks & $19^{\circ} 09.483^{\prime}$ & $40^{\circ} 18.065^{\prime}$ & LT630846 & LT630968-9 \\
\hline SA2634 & Pavona diffluens & RA & Ablo Reef, Farasan Banks & $18^{\circ} 42.340^{\prime}$ & $40^{\circ} 39.240^{\prime}$ & LT630847 & LT630970 \\
\hline SA2640 & Pavona explanulata & RA & Ablo Reef, Farasan Banks & $18^{\circ} 42.340^{\prime}$ & $40^{\circ} 39.240^{\prime}$ & LT630848 & LT630971-2 \\
\hline SA2652 & Pavona diffluens & RA & Ablo Reef, Farasan Banks & $18^{\circ} 42.340^{\prime}$ & $40^{\circ} 39.240^{\prime}$ & LT630849 & LT630973-4 \\
\hline SA2653 & Pavona frondifera & MT & Al-Qunfidhah, Farasan Banks & $19^{\circ} 00.186^{\prime}$ & $40^{\circ} 16.993^{\prime}$ & LT630850 & LT630975-6 \\
\hline SA2654 & Leptoseris scabra & MT & Al-Qunfidhah, Farasan Banks & $19^{\circ} 00.186^{\prime}$ & $40^{\circ} 16.993^{\prime}$ & LT630851 & LT630977-8 \\
\hline SA2658 & Pavona maldivensis & MT & Al-Qunfidhah, Farasan Banks & $19^{\circ} 00.186^{\prime}$ & $40^{\circ} 16.993^{\prime}$ & LT630852 & LT630979 \\
\hline SA2665 & Leptoseris mycetoseroides & RA & Al-Qunfidhah, Farasan Banks & $19^{\circ} 00.186^{\prime}$ & $40^{\circ} 16.993^{\prime}$ & LT630853 & LT630980-1 \\
\hline SA2667 & Pavona maldivensis & RA & Al-Qunfidhah, Farasan Banks & $19^{\circ} 00.186^{\prime}$ & $40^{\circ} 16.993^{\prime}$ & LT630854 & LT630982 \\
\hline SA2668 & Gardineroseris planulata & RA & Al-Qunfidhah, Farasan Banks & $19^{\circ} 00.186^{\prime}$ & $40^{\circ} 16.993^{\prime}$ & LT630855 & LT630983-4 \\
\hline SA2675 & Pavona varians & RA & Al-Qunfidhah, Farasan Banks & $19^{\circ} 00.186^{\prime}$ & $40^{\circ} 16.993^{\prime}$ & LT630856 & LT630985-6 \\
\hline SA2698 & Leptoseris glabra & RA & Al-Qunfidhah, Farasan Banks & $19^{\circ} 00.186^{\prime}$ & $40^{\circ} 16.993^{\prime}$ & LT630857 & LT630987-8 \\
\hline
\end{tabular}

For each specimen, the voucher code, identification of the matching specimen, collector, collection locality, latitude (N), longitude (E), and EMBL accession numbers of each molecular marker are provided. FB = F. Benzoni; MT = M. Tietbohl; RA = R. Arrigoni; TIT = T.I. Terraneo

differences (Table 2). Notably, we recorded L. glabra from the $\mathrm{RS}$ for the first time. However, it is possible that previous authors recorded it as L. explanata due to its similar morphology. According to Dinesen (1980), the material identified as L. explanata by Veron and Pichon (1980; figs 71-82) actually belongs to L. glabra. Dinesen (1980) also indicated 
Table 3 List of Agariciidae morphospecies collected in the Red Sea (RS) and relative genetic assignment from IGR and ITS1 molecular markers

\begin{tabular}{lll}
\hline & IGR & ITS1 \\
\hline Gardineroseris planulata & CLADE V & CLADE V \\
Pavona cactus & CLADE XIV & CLADE XIV \\
Pavona clavus & CLADE VI & CLADE VI \\
Pavona danai & CLADE XIV & CLADE XIV \\
Pavona decussata & CLADE IV & CLADE IV \\
Pavona diffluens & CLADE XII & Unresolved \\
Pavona explanulata & CLADES VIII-X & Unresolved \\
Pavona frondifera & CLADE XIV & CLADE XIV \\
Pavona maldivensis & CLADE II & CLADE II \\
Pavona varians & CLADE I & CLADES I-IV \\
Pavona venosa & CLADE I & CLADES I-IV \\
Leptoseris explanata & CLADE XII & Unresolved \\
Leptoseris fragilis & CLADE III & CLADE III \\
Leptoseris glabra & CLADE XII & Unresolved \\
Leptoseris cf. hawaiiensis & CLADE XII & Unresolved \\
Leptoseris incrustans & CLADE XII & Unresolved \\
Leptoseris mycetoseroides & CLADES IX-XI & Unresolved \\
Leptoseris scabra & CLADE XII & Unresolved \\
Leptoseris sp & CLADE VII & CLADE VII \\
Leptoseris yabei & CLADE XIII & CLADE XIII \\
\hline
\end{tabular}

that the type material of $L$. explanata shown and described in Yabe and Sugiyama (1941: pl. 63, fig. 3e) is morphologically distinct from $L$. glabra, as she described in her revision of Leptoseris (Dinesen 1980). In our identifications, we followed the original descriptions of these two morphospecies and considered them as morphologically distinct following Dinesen (1980). Nevertheless, the recovery of specimens ascribed to these two species in the same lineage with other Leptoseris merits for further investigation into the relationship between these species. While the existing confusion in the literature concerning $L$. explanata and $L$. glabra is easily explained based on their undeniable similarities in terms of calice size and arrangement, they are both markedly distinct from the other morphospecies recovered in the same clade having smaller calices and more numerous septa (Fig. 2). Easily recognizable and common shallow-water species such as G. planulata, P. cactus, $P$. decussata, P. explanulata, P. maldivensis, $P$. varians, $L$. explanata, $L$. hawaiiensis, $L$. mycetoseroides, L. scabra, and L. yabei were recorded by Scheer and Pillai (1983), Sheppard and Sheppard (1991), Veron (2000), and this work. Compared to Sheppard and Sheppard (1991) and Veron (2000), we did not record $P$. duerdeni and L. foliosa during our collection. The former species is rare in the RS, although it can form conspicuous colonies in low-energy waters (Veron 2000), whereas the latter species is uncommon and preferentially found in deep-water habitats $(>30 \mathrm{~m}$ ) (Sheppard and
Sheppard 1991). This work did not investigate mesophotic coral ecosystems, potentially explaining why these species were likely missed. The family Agariciidae is among the most abundant coral families in deep-water oceanic habitats (Lesser et al. 2009). Therefore, more species are likely to occur in deeper waters of the RS. Leptoseris often shows an increasing abundance with depth in the IO (Bouchon 1981) and in Hawaii (Kahng and Kelley 2007), where it dominates hard substrates between 60 and $120 \mathrm{~m}$ and is, instead, rare in shallow-water reefs. Luck et al. (2013) also found cryptic lineages of Leptoseris across depth gradients in Hawaii, and several studies showed limited larval dispersal, genetic segregation, and low gene flow between shallow and mesophotic agariciid reef corals (Bongaerts et al. 2013, 2015; Pochon et al. 2015). Bongaerts et al. (2013) showed a division of Agaricia species and associated Symbiodinium into two main genetic lineages that matched a clear bathymetric distribution. For these reasons, we caution others to consider our presented survey as fully representative of only the shallow-water genetic diversity of Agariciidae from the Saudi Arabian RS; we strongly encourage further investigations of mesophotic reefs.

Regarding the molecular information, our work further highlighted the hypothesis that some regions of the mitochondrial DNA of corals can be informative in defining boundaries among closely related taxa. Despite the well-documented slow evolution of Scleractinia mitochondrial DNA (Shearer et al. 2002; Hellberg 2006; Huang et al. 2008), recent works have found that some mitochondrial non-coding regions show rates of interspecific polymorphisms comparable to these of nuclear loci and can be phylogenetically informative at low taxonomic levels (Kitahara et al. 2016). The IGR sequenced in the present work has been previously used for delimiting species boundaries in several scleractinian families and genera, including the families Merulinidae Verrill, 1865 and Agariciidae (Kitahara et al. 2016), the genus Pachyseris Milne Edwards \& Haime, 1849 (Terraneo et al. 2014), and the genera Sclerophyllia Klunzinger, 1879, Homophyllia Brüggemann, 1877, and Micromussa Veron, 2000 (Arrigoni et al. 2015, 2016b). Ribosomal DNA is widely used for lowlevel taxonomic comparisons in corals, particularly due to high interspecific divergence between the two internal transcribed spacers regions, ITS1 and ITS2 (Kitahara et al. 2016). In the present study, the phylogeny reconstruction based on ITS1 was poorly resolved, as it was characterized by a large basal polytomy and several species were not differentiated. The absence of genetic differentiation among the analyzed species may be explained by insufficient resolution of the ITS1 locus. Hence, we encourage the investigation of further molecular markers and modern genome-wide sequencing techniques that could provide strong phylogenomic analysis to help better determine species boundaries (Pante et al. 2015).

This work raises several questions regarding the classical definition of genera and species boundaries within the 
Agariciidae that will require more in-depth observations of skeletal micromorphology before a formal taxonomic revision of the family is proposed. As previously reported by Luck et al. (2013), our mitochondrial phylogeny reconstruction confirmed that Pavona and Leptoseris are not monophyletic. Our molecular analyses (based on IGR and ITS1) revealed for the first time that the monotypic Gardineroseris is closely related to both Pavona and Leptoseris and it nests within them. The genetic information does not support the morphology-based distinction among these three genera (Scheer and Pillai 1974; Dinesen 1980) and suggests the presence of a single, speciesrich genus. However, any taxonomic reclassification is not recommended until a comprehensive phylogenetic reconstruction of the Agariciidae, including all seven extant genera and sequencing of slow-evolving loci such as the mitochondrial $\mathrm{COI}$ and $16 \mathrm{~S}$ rDNA genes and the nuclear $28 \mathrm{~S}$ region, is conducted (Fukami et al. 2008; Huang et al. 2008). Indeed, non-coding regions are usually considered to be poorly informative at high taxonomic levels because homoplasy caused by repeated mutations in saturated positions is thought to undermine the phylogenetic signal (Kelchner 2000). At the species level, the IGR and ITS1 phylogeny reconstructions revealed the presence of three species complexes (Fig. 3, Table 3). On one hand, the recovery of the two species complexes composed of the frondose and highly plastic $P$. cactus, $P$. danai, and $P$. frondifera and of the encrusting and highly carinated $P$. varians and P. venosa (Veron and Pichon 1980) could be morphologically plausible. Indeed, these species display similar colony morphology, related collines and carinae, comparable corallite dimension and organization, and previous taxonomists have identified these morphological affinities (Vaughan 1918; Crossland 1952; Veron and Pichon 1980; Scheer and Pillai 1983; Veron 2000). The recovery of a molecular clade including L. explanata, Leptoseris cf. hawaiiensis, L. scabra, L. incrustans, L. glabra, and $P$. diffluens was unexpected. Although $P$. diffluens may be mistaken for massive parts of $P$. explanulata (Sheppard and Sheppard 1991), it does not resemble any Leptoseris species ascribed to this molecular group. Moreover, as mentioned earlier in this discussion, the Leptoseris morphospecies recovered in this one cohesive lineage in the RS do display remarkable differences in terms of colony growth form, calice size and organization, and septocostae thickness, with the notable exception of L. glabra and L. explanata (Fig. 2). A similar situation has been described in the genus Stylophora from the RS (Arrigoni et al. 2016c), where different morphospecies, two of which are endemic to the RS, could not be differentiated based on genetic results. Several hypotheses can be suggested to explain this finding, such as taxonomic misidentification, uninformative morphological characters, non-suitable molecular loci, or incipient speciation.

In conclusion, we investigated the genetic diversity of Agariciidae from the isolated Saudi Arabian RS and provide a regional genetic database for future molecular comparisons between the RS and other localities. The partial disagreement between morphology-based taxonomy and genetic results highlights that agariciid systematics is poorly understood and that the current family taxonomy does not truly represent the evolutionary relationships at the genus or species levels. A combined morpho-molecular approach with a strong focus on skeletal micromorphology is likely necessary to better clarify the boundaries within the family and revise its taxonomy, as previously demonstrated for the agariciid Dactylotrochus (Kitahara et al. 2012) and several other scleractinian families (Kitahara et al. 2016). The molecular phylogeny of Agariciidae is still incomplete because only a few regions and species have been genetically characterized to date (Maté 2003; Moothien Pillay et al. 2006; Benzoni et al. 2012; Luck et al. 2013; Pochon et al. 2015; Waheed et al. 2015). Therefore, a more global sampling effort with a larger number of taxa and more genetic data, in addition to detailed comparative micromorphological analysis, are needed and necessary before a robust molecular hypothesis can be produced and the agariciids fully resolved.

Acknowledgments This research was undertaken in accordance with the policies and procedures of the King Abdullah University of Science and Technology (KAUST). Permissions relevant for KAUST to undertake the research have been obtained from the applicable governmental agencies in the Kingdom of Saudi Arabia. We wish to thank the captain and crew of the MV Dream Master, the KAUST Coastal and Marine Resources Core Lab, A. Gusti (KAUST), and T.H. Sinclair-Taylor (KAUST). T.I.T. and R.A. gratefully acknowledge J.D. DiBattista (CURTIN) and P. Saenz-Agudelo (UACH) for their assistance at KAUST. This project was supported by funding from KAUST (award nos. URF/1/1389-01-01 and FCC/1/1973-07, and baseline research funds to M.L.B.).

\section{References}

Arrigoni R, Stefani F, Pichon M, Galli P, Benzoni F (2012) Molecular phylogeny of the robust clade (Faviidae, Mussidae, Merulinidae, and Pectiniidae): an Indian Ocean perspective. Mol Phylogenet Evol 65:183-193

Arrigoni R, Berumen ML, Terraneo TI, Caragnano A, Bouwmeester J, Benzoni F (2015) Forgotten in the taxonomic literature: resurrection of the scleractinian coral genus Sclerophyllia (Scleractinia, Lobophylliidae) from the Arabian peninsula and its phylogenetic relationships. Syst Biodivers 13:140-163

Arrigoni R, Berumen ML, Chen CA, Terraneo TI, Baird AH, Payri C, Benzoni F (2016a) Species delimitation in the reef coral genera Echinophyllia and Oxypora (Scleractinia, Lobophylliidae) with a description of two new species. Mol Phylogenet Evol 105:146-159

Arrigoni R, Benzoni F, Huang D, Fukami H, Chen CA, Berumen ML, Hoogenboom M, Thomson DP, Hoeksema BW, Budd AF, Zayasu Y, Terraneo TI, Kitano YF, Baird AH (2016b) When forms meet genes: revision of the scleractinian genera Micromussa and Homophyllia (Lobophylliidae) with a description of two new species and one new genus. Contrib Zool 85:387-422

Arrigoni R, Benzoni F, Terraneo TI, Caragnano A, Berumen ML (2016c) Recent origin and semi-permeable species boundaries in the 
scleractinian coral genus Stylophora from the Red Sea. Sci Rep 6: 34612

Arrigoni R, Berumen ML, Huang D, Terraneo TI, Benzoni F (2017) Cyphastrea (Cnidaria: Scleractinia: Merulinidae) in the Red Sea: phylogeny and a new reef coral species. Invertebr Syst 31:141-156

Benzoni F, Arrigoni R, Stefani F, Stolarski J (2012) Systematics of the coral genus Craterastrea (Cnidaria, Anthozoa, Scleractinia) and description of a new family through combined morphological and molecular analyses. Syst Biodivers 10:417-433

Berumen ML, Hoey AS, Bass WH, Bouwmeester J, Catania D, Cochran JE, Khalil MT, Miyake S, Mughal MR, Spaet JL, Saenz-Agudelo P (2013) The status of coral reef ecology research in the Red Sea. Coral Reefs 32:737-748

Bongaerts P, Frade PR, Ogier JJ, Hay KB, Van Bleijswijk J, Englebert N, Vermeij MJ, Bak RP, Visser PM, Hoegh-Guldberg O (2013) Sharing the slope: depth partitioning of agariciid corals and associated Symbiodinium across shallow and mesophotic habitats $(2-60 \mathrm{~m})$ on a Caribbean reef. BMC Evol Biol 13:205

Bongaerts P, Frade PR, Hay KB, Englebert N, Latijnhouwers KR, Bak RP, Vermeij MJ, Hoegh-Guldberg O (2015) Deep down on a Caribbean reef: lower mesophotic depths harbor a specialized coral-endosymbiont community. Sci Rep 5:7652

Bouchon C (1981) Quantitative study of the scleractinian coral communities of a fringing reef of Reunion Island (Indian Ocean). Mar Ecol Prog Ser 4:273-288

Castresana J (2000) Selection of conserved blocks from multiple alignments for their use in phylogenetic analysis. Mol Biol Evol 17:540 552

Coleman RR, Eble JA, DiBattista JD, Rocha LA, Randall JE, Berumen ML, Bowen BW (2016) Regal phylogeography: range-wide survey of the marine angelfish Pygoplites diacanthus reveals evolutionary partitions between the Red Sea, Indian Ocean, and Pacific Ocean. Mol Phylogenet Evol 100:243-253

Crossland C (1952) Madreporaria, Hydrocorallinae, Heliopora and Tubipora. Br Mus Nat Hist 6:85-257

DiBattista JD, Berumen ML, Gaither MR, Rocha LA, Eble JA, Choat JH, Craig MT, Skillings DJ, Bowen BW (2013) After continents divide: comparative phylogeography of reef fishes from the Red Sea and Indian Ocean. J Biogeogr 40:1170-1181

DiBattista JD, Waldrop E, Rocha LA, Craig MT, Berumen ML, Bowen BW (2015) Blinded by the bright: a lack of congruence between colour morphs, phylogeography and taxonomy for a cosmopolitan Indo-Pacific butterflyfish, Chaetodon auriga. J Biogeogr 42:19191929

DiBattista JD, Howard Choat J, Gaither MR, Hobbs JP, Lozano-Cortés DF, Myers RF, Paulay G, Rocha LA, Toonen RJ, Westneat MW, Berumen ML (2016a) On the origin of endemic species in the Red Sea. J Biogeogr 43:13-30

DiBattista JD, Roberts MB, Bouwmeester J, Bowen BW, Coker DJ, Lozano-Cortés DF, Howard Choat J, Gaither MR, Hobbs JP, Khalil MT, Kochzius M, Myers RF, Paulay G, Robitzch VSN, Saenz-Agudelo P, Salas E, Sinclair-Taylor TH, Toonen RJ, Westneat MW, Williams ST, Berumen ML (2016b) A review of contemporary patterns of endemism for shallow water reef fauna in the Red Sea. J Biogeogr 43:423-439

Dinesen ZD (1980) A revision of the coral genus Leptoseris (Scleractinia: Fungiina: Agariciidae). Mem Queensl Mus 20:181-235

Ehrenberg CG (1834) Beiträge zur physiologischen Kenntniss der Corallenthiere im Allgemeinen, und besonders des Rothen Meeres, nebst einem Versuche zur physiologischen Systematik derselben. Abhandlungen der Königlichen Akademie der Wissenschaften, Berlin

Ekman S (1953) Zoogeography of the sea. Sidgwick \& Jackson, London

Flot JF (2007) Champuru 1.0: a computer software for unraveling mixtures of two DNA sequences of unequal lengths. Mol Ecol Resour 7: 974-977
Flot JF (2010) SeqPHASE: a web tool for interconverting PHASE input/ output files and FASTA sequence alignments. Mol Ecol Resour 10: $162-166$

Forskål P (1775) Descriptiones animalium, avium, amphibiorum, piscium, insectorum, vermium; quæ in itinere orientali observavit Petrus Forskål. Hauniæ, Heineck et Faber, Copenhagen

Fricke HW, Knauer B (1986) Diversity and spatial pattern of coral communities in the Red Sea upper twilight zone. Oecologia 71:29-37

Fricke HW, Vareschi E, Schlichter D (1987) Photoecology of the coral Leptoseris fragilis in the Red Sea twilight zone (an experimental study by submersible). Oecologia 73:371-381

Fukami H, Chen CA, Budd AF, Collins A, Wallace C, Chuang YY, Chen C, Dai CF, Iwao K, Sheppard C, Knowlton N (2008) Mitochondrial and nuclear genes suggest that stony corals are monophyletic but most families of stony corals are not (order Scleractinia, class Anthozoa, phylum Cnidaria). PLoS One 3:e3222

Guindon S, Gascuel O (2003) A simple, fast, and accurate algorithm to estimate large phylogenies by maximum likelihood. Syst Biol 52: 696-704

Hall TA (1999) BioEdit: a user-friendly biological sequence alignment editor and analysis program for Windows 95/98/NT. Nucleic Acids Symp Ser 41:95-98

Hellberg ME (2006) No variation and low synonymous substitution rates in coral mtDNA despite high nuclear variation. BMC Evol Biol 6:24

Hinderstein LM, Marr JCA, Martinez FA, Dowgiallo MJ, Puglise KA, Pyle RL, Zawada DG, Appeldoorn R (2010) Theme section on "Mesophotic coral ecosystems: characterization, ecology, and management". Coral Reefs 29:247-251

Hodge JR, van Herwerden L, Bellwood DR (2014) Temporal evolution of coral reef fishes: global patterns and disparity in isolated locations. J Biogeogr 41:2115-2127

Huang D, Meier R, Todd PA, Chou LM (2008) Slow mitochondrial COI sequence evolution at the base of the metazoan tree and its implications for DNA barcoding. J Mol Evol 66:167-174

Kahng SE, Kelley CD (2007) Vertical zonation of megabenthic taxa on a deep photosynthetic reef (50-140 m) in the Au'au Channel, Hawaii. Coral Reefs 26:679-687

Kahng SE, Garcia-Sais JR, Spalding HL, Brokovich E, Wagner D, Weil E, Hinderstein L, Toonen RJ (2010) Community ecology of mesophotic coral reef ecosystems. Coral Reefs 29:255-275

Kahng SE, Copus JM, Wagner D (2014) Recent advances in the ecology of mesophotic coral ecosystems (MCEs). Curr Opin Environ Sustain 7:72-81

Katoh K, Standley DM (2013) MAFFT multiple sequence alignment software version 7: improvements in performance and usability. Mol Biol Evol 30:772-780

Kelchner SA (2000) The evolution of non-coding chloroplast DNA and its application in plant systematics. Ann Mo Bot Gard 87:482-498

Kitahara MV, Cairns SD, Stolarski J, Blair D, Miller DJ (2010) A comprehensive phylogenetic analysis of the Scleractinia (Cnidaria, Anthozoa) based on mitochondrial CO1 sequence data. PLoS One 5(7):e11490. doi:10.1371/journal.pone.0011490

Kitahara MV, Stolarski J, Cairns SD, Benzoni F, Stake JL, Miller DJ (2012) The first modern solitary Agariciidae (Anthozoa, Scleractinia) revealed by molecular and microstructural analysis. Invertebr Syst 26:303-315

Kitahara MV, Fukami H, Benzoni F, Huang D (2016) The new systematics of Scleractinia: integrating molecular and morphological evidence. In: Goffredo S, Dubinsky Z (eds) The Cnidaria, past, present and future: the world of Medusa and her sisters. Springer, Dordrecht, pp 41-60

Kitano YF, Benzoni F, Arrigoni R, Shirayama Y, Wallace CC, Fukami H (2014) A phylogeny of the family Poritidae (Cnidaria, Scleractinia) based on molecular and morphological analyses. PLoS One 9: e98406 
Klunzinger CB (1870) Synopsis der fische des Rothen Meeres. C. Ueberreuter'shBuchdruckerei, Wien

Klunzinger CB (1877) Die Korallthiere des Rothen Meeres. Gutmann'schen, Berlin

Ladner JT, Palumbi SR (2012) Extensive sympatry, cryptic diversity and introgression throughout the geographic distribution of two coral species complexes. Mol Ecol 21:2224-2238

Lamarck JBP (1816) Histoire naturelle des Animaux sans Vertèbres, présentant les caractères généraux et particuliers de ces animaux, leur distribution, leurs classes, leurs familles, leurs genres, et la citation des principales espèces qui s'y rapportent; précédée d'une Introduction offrant la détermination des caractères essentiels de l'animal, sa distinction du végétal et des autres corps naturels, enfin, l'exposition des principes fondomentaux de la zoologie. Déterville $\&$ Verdière, Paris

Lesser MP, Slattery M, Leichter JJ (2009) Ecology of mesophotic coral reefs. J Exp Mar Biol Ecol 375:1-8

Librado P, Rozas J (2009) DnaSP v5: a software for comprehensive analysis of DNA polymorphism data. Bioinformatics 25:1451-1452

Loya Y, Genin A, el-Zibdeh M, Naumann MS, Wild C (2014) Reviewing the status of coral reef ecology of the Red Sea: key topics and relevant research. Coral Reefs 33:1179-1180

Luck DG, Forsman ZH, Toonen RJ, Leicht SJ, Kahng SE (2013) Polyphyly and hidden species among Hawai i's dominant mesophotic coral genera, Leptoseris and Pavona (Scleractinia: Agariciidae). Peer J 1:e132

Maragos JE, Jokiel PL (1986) Reef corals of Johnston atoll: one of the world's most isolated reefs. Coral Reefs 4:141-150

Maté J (2003) Ecological, genetic, and morphological differences among three Pavona (Cnidaria: Anthozoa) species from the Pacific coast of Panama. Mar Biol 142:427-440

Moothien Pillay KR, Aasahida T, Chen CA, Terashima H, Ida H (2006) ITS ribosomal DNA distinctions and the genetic structures of populations of two sympatric species of Pavona (Cnidaria: Scleractinia) from Mauritius. Zool Stud 45:132-144

Nishihira M, Veron JEN (1995) Hermatypic corals of Japan. Kaiyusha, Tokyo

Obura D (2012) The diversity and biogeography of western Indian Ocean reef-building corals. PLoS One 7:e45013

Pante E, Abdelkrim J, Viricel A, Gey D, France SC, Boisselier MC, Samadi S (2015) Use of RAD sequencing for delimiting species. Heredity 114(5):450-459

Pillai CSG, Scheer G (1976) Report on the stony corals from the Maldive Archipelago. Results of the Xarifa Expedition 1957/58. Zoologica, Stuttgart 43(126): 1-83

Pochon X, Forsman ZH, Spalding HL, Padilla-Gamiño JL, Smith CM, Gates RD (2015) Depth specialization in mesophotic corals (Leptoseris spp.) and associated algal symbionts in Hawai'i. R Soc Open Sci 2:140351

Posada D, Crandall KA (1998) MODELTEST: testing the model of DNA substitution. Bioinformatics 14(9):817-818

Rambaut A, Drummond AJ (2007) Tracer v1.4. Available from http:// beast.bio.ed.ac.uk/Tracer

Richards ZT, Berry O, van Oppen MJ (2016) Cryptic genetic divergence within threatened species of Acropora Coral from the Indian and Pacific oceans. Conserv Genet 17:577-591

Ronquist F, Huelsenbeck JP (2003) MrBayes 3: Bayesian phylogenetic inference under mixed models. Bioinformatics 19:1572-1574

Rooney J, Donham E, Montgomery A, Spalding H, Parrish F, Boland R, Fenner D, Gove J, Vetter O (2010) Mesophotic coral ecosystems in the Hawaiian archipelago. Coral Reefs 29:361-367

Scheer G, Pillai CSG (1974) Report on the Scleractinia from the Nicobar Islands. E. Schweizerbart'sche Verlagsbuchhandlung, Stuttgart
Scheer G, Pillai CSG (1983) Report on the stony corals from the Red Sea. E. Schweizerbart'sche Verlagsbuchhandlung, Stuttgart

Shearer TL, Van Oppen MJH, Romano SL, Wörheide G (2002) Slow mitochondrial DNA sequence evolution in the Anthozoa (Cnidaria). Mol Ecol 11:2475-2487

Sheppard CRC, Sheppard ALS (1991) Corals and coral communities of Saudi Arabia. Fauna Saudi Arabia 12:1-170

Sheppard CRC, Price A, Roberts C (1992) Marine ecology of the Arabian region. Academic Press, London

Stefani F, Benzoni F, Yang SY, Pichon M, Galli P, Chen CA (2011) Comparison of morphological and genetic analyses reveals cryptic divergence and morphological plasticity in Stylophora (Cnidaria, Scleractinia). Coral Reefs 30:1033-1049

Stephens M, Smith N, Donnelly P (2001) A new statistical method for haplotype reconstruction from population data. Am J Hum Genet 68:978-989

Swofford DL (2002) PAUP*. Phylogenetic Analysis Using Parsimony (*and other methods). Version 4. Sinauer Associates, Sunderland

Terraneo TI, Berumen ML, Arrigoni R, Waheed Z, Bouwmeester J, Caragnano A, Stefani F, Benzoni F (2014) Pachyseris inattesa sp. n. (Cnidaria, Anthozoa, Scleractinia): a new reef coral species from the Red Sea and its phylogenetic relationships. ZooKeys 433:1-33

Terraneo TI, Benzoni F, Arrigoni R, Berumen ML (2016) Species delimitation in the coral genus Goniopora (Scleractinia, Poritidae) from the Saudi Arabian Red Sea. Mol Phylogenet Evol 102:278-294

Vaughan TW (1918) Some shoal-water corals from Murray Island (Australia), Cocos-Keeling Islands, and Fanning Island. Carnegie Institution of Washington, Washington

Vaughan TW, Wells JW (1943) Revision of the suborders, families, and genera of the Scleractinia. Geol Soc Am Special Paper 44:1-394

Veron JEN (2000) Corals of the world. Australian Institute of Marine Science, Townsville

Veron JEN, Pichon M (1980) Scleractinia of eastern Australia. Part III: families Agariciidae, Siderastreidae, Fungiidae, Oculinidae, Merulinudae, Mussidae, Pectiniidae, Caryophylliidae, Dendrophylliidae. Aust Inst Mar Sci Monogr 4:1-422

Veron J, Stafford-Smith M, DeVantier L, Turak E (2015) Overview of distribution patterns of zooxanthellate Scleractinia. Front Mar Sci 1: 81

Waheed Z, Hoeksema BW (2014) Diversity patterns of scleractinian corals at Kota Kinabalu, Malaysia, in relation to exposure and depth. Raffles Bull Zool 62:66-82

Waheed Z, Benzoni F, van der Meij SE, Terraneo TI, Hoeksema BW (2015) Scleractinian corals (Fungiidae, Agariciidae and Euphylliidae) of Pulau Layang-Layang, Spratly Islands, with a note on Pavona maldivensis (Gardiner, 1905). ZooKeys 517:1-37

Wei NW, Wallace CC, Dai CF, Pillay KRM, Chen CA (2006) Analyses of the ribosomal internal transcribed spacers (ITS) and $5.8 \mathrm{~S}$ gene indicate that extremely high rDNA heterogeneity is a unique feature in the scleractinian coral genus Acropora (Scleractinia; Acroporidae). Zool Stud 45:404-418

Wells JW (1956) Scleractinia. In: Moore RC (ed) Treatise on invertebrate paleontology, part F (Coelenterata). The University of Kansas Press, Lawrence, pp F328-F444

WoRMS (2016) World register of marine species. Available from http:// www.marinespecies.org at VLIZ. Accessed 29 Sep 2016

Yabe H, Sugiyama T (1941) Recent reef-building corals from Japan and the South Sea Islands under the Japanese mandate II. The Science reports of the Tôhoku Imperial University, Sendai. 2nd Series (Geologie) Special Volume 2:67-91

Ziegler M, Roder CM, Büchel C, Voolstra CR (2015) Mesophotic coral depth acclimatization is a function of host-specific symbiont physiology. Front Mar Sci 2:1-4 